\title{
Are Canadian hospitals leading by example to promote smoke-free hospital properties? Rationale, challenges and opportunities
}

\author{
Kerrie E Luck* \\ School of Graduate Studies, University of New Brunswick, Saint John, NB, Canada
}

Received: March 9, 2016

DOI: $10.5430 /$ jha.v5n4p9

\author{
Accepted: April 12, 2016 \\ Online Published: April 20, 2016 \\ URL: http://dx.doi.org/10.5430/jha.v5n4p9
}

\begin{abstract}
Knowing the devastation of tobacco use and the evidence to support proven tobacco reduction approaches, such as smoke-free hospital property policies, are Canadian hospitals doing all they can to lead by example? This paper explores the background and diverse views on smoke-free hospital properties to illuminate the rationale, challenges and opportunities of this important healthcare initiative. Currently, some hospitals in Canada have transitioned to smoke-free properties; however, many still allow smoking in designated areas or do not have any policies in place. Fear, speculation and reservations around compliance, leadership, negative perceptions, safety and patient care are some of the reasons that appear to be stalling progress in many healthcare facilities; nevertheless, the evidence supporting the implementation of comprehensive smoke-free hospital property policies far outweighs the concerns. Key considerations for successful policy implementation include: leadership and enforcement; systematic tobacco dependence treatment; and elimination of designated smoking areas (DSA's) and policy exclusions. Hospitals are ideal institutions to continue the downward trend in tobacco use prevalence. Through smoke-free property policies, Canadian hospitals can make a significant impact and lead by example in their communities by creating opportunities to promote healthy choices, protecting individuals from exposure to environmental tobacco smoke (ETS), supporting those who are trying to quit or who have quit smoking and by sending a clear message that smoking and exposure to tobacco smoke is harmful. As witnessed though the learnings of leading hospitals, transitioning to a smoke-free hospital property is achievable.
\end{abstract}

Key Words: Tobacco smoke pollution, Secondhand smoke, Environmental tobacco smoke, Smoke-free policy, Hospital, Smoke

\section{INTRODUCTION}

Smoking tobacco is the leading preventable cause of premature disease and death, costing the Canadian economy an estimated 18.4 billion dollars per year in both direct and indirect costs. ${ }^{[1]}$ Tobacco use is predicted to kill approximately 37,000 Canadians annually. ${ }^{[2]}$ Smoking and exposure to environmental tobacco smoke (ETS) has been causally linked to diseases of virtually every organ of the body, Including cancer, cardiovascular disease, respiratory disease, kidney disease and Type 2 diabetes, just to name a few. ${ }^{[3]}$ The U.S. Department of Health and Human Services Surgeon General's report (2014) ${ }^{[3]}$ warns there is no safe level of exposure to the over 7,000 chemicals found in ETS; even sporadic exposure is harmful. Exposure can also exacerbate breathing difficulties for individuals with respiratory disease and trigger asthma attacks in predisposed individuals. For many it can also irritate their eyes, nose and/or throat. ${ }^{[3]}$

\footnotetext{
* Correspondence: Kerrie E Luck, MSc. OT; Email: kerrieluck@ hotmail.com; Address: School of Graduate Studies, University of New Brunswick, Saint John, NB, Canada.
} 
identified that $14.6 \%$ of Canadians age 15 and older still smoke. Although many gains have been made over the years with direction from Canada's Federal Tobacco Control Strategy (FTCS), the decline in smoking prevalence rates has slowed, if not plateaued in some provinces; nearly 4.2 million Canadians still smoke. ${ }^{[4]}$ Even though society's attitudes have changed over the last few decades in terms of tobacco use, unless necessary action is taken to preserve the gains made and accelerate the decline in the prevalence of tobacco use, the burden of smoking-attributable morbidity and mortality will remain at undesirable levels. ${ }^{[3]}$ Both the US Surgeon General's report and Canada's FTCS call for comprehensive approaches and evidence-based interventions that encourage smoking cessation and the prevention of youth smoking, such as, smoke-free policies and barrier-free access to smoking cessation supports. The Surgeon General suggests that "With intense use of proven interventions, we can save lives and reduce health care costs". ${ }^{[3]}$

Canada's national strategy for tobacco control steering committee acknowledge there is no single approach to solving the epidemic of death and disease resulting from tobacco use. ${ }^{[5]}$ They believe effective tobacco control demands an array of comprehensive and coordinated strategies complementary at local, provincial/territorial, national and international levels. The four goals identified in their national framework to identify and support collaboration in tobacco reduction efforts by government, non-government, individuals and communities include: preventing tobacco use; smoking/tobacco cessation; protection from exposure to second-hand smoke; and the denormalization of tobacco use and industry's marketing tactics to promote healthier social attitudes. They call on regional health authorities to use the national tobacco control strategy as a guide for action and provide leadership and resources to support tobacco control.

Comprehensive smoke-free hospital property policies are one such example where all four goals can be met. Knowing the devastation of tobacco use and the evidence to support proven tobacco reduction approaches, such as smokefree hospital property policies, are Canadian hospitals doing all they can to lead by example? For this review, several databases were used to gather information to explore this question in more detail, including CINAHL, PubMed, EBSCO, ProQuest, and Google Scholar. Search terms included "secondhand smoke", "ETS", "smoke-free policy", "hospital" and "smoke". Searches were restricted to the English language and publication dates of 1990 or later. This restricted time frame was chosen based on the movement in the early 1990s for indoor smoke-free hospital policies and legislation as this would capture any published literature on outdoor smoke-free hospital bans and policies happening thereafter.
The remainder of this paper will explore the background and diverse views in the published literature on smoke-free hospital properties to illuminate the rationale, challenges and opportunities of this important healthcare initiative.

\section{BACKGROUND AND RATIONALE FOR SMOKE-FREE HOSPITAL PROPERTY POLICIES}

South of the Canadian border, smoke-free hospital policies have continued to expand to include all hospital properties, in partial response to the gathering of smokers found at entrances of the hospitals. ${ }^{[6]}$ By 2008, 45\% of accredited American hospitals had already adopted smoke-free campus policies with another $15 \%$ reporting they were actively planning to become a smoke-free hospital property. ${ }^{[6]}$ Williams et al., ${ }^{[6]}$ estimated that by the end of 2009, the majority of US hospitals would be smoke-free campuses. This same trend started in Canada in 2002 with the Calgary Health Region being the first health region to ban smoking on hospital property. ${ }^{[7]}$ And though some Canadian hospitals have followed suit, many still allow smoking on their properties or have only partial bans in place, including policy exceptions/exclusions and designated smoking areas (DSA's). ${ }^{[8]}$

\subsection{Legislation and accreditation}

In 2009, PEI was the first province to enact legislation prohibiting smoking on hospital property, with the exception of psychiatric hospitals. ${ }^{[8]}$ The Ontario government recently amended their Smoke-free Ontario Act to phase in 100\% smoke-free hospital properties across their province, including psychiatric facilities, by January, 2018. ${ }^{[9]}$ To date, PEI and Ontario are still the only provinces with legislation for smoke-free hospital properties; however, a number of municipalities have passed bylaws to ban smoking on hospital properties. $^{[8]}$

The Joint Commission, a nationwide hospital accreditation body, played a significant contributing role in the advancements of smoke-free policies in the United States through the creation of smoke-free hospital standards. ${ }^{[10]}$ Although not a requirement, The Joint Commission also supports hospital facilities to move towards a smoke free property based on the health risks for individuals who smoke, health risks of exposure to ETS, and the risk of fire. ${ }^{[1]}$ Accreditation Canada, a Canadian organization similar to the American Joint Commission, accredits over 6,000 healthcare sites across the country while striving to ensure quality health services for all. ${ }^{[12]}$ They advocate that quality, safety and efficiency of care will be improved through their standards and accreditation programs, yet to date they do not hold hospitals accountable to any specific standards or guidelines for smoking. ${ }^{[12]}$ As 
advocated in a discussion paper by Balmford, Leifert and Jaehne, ${ }^{[13]}$ providing hospitalized patients with smoking cessation supports and information to help change behaviors to benefit their health is "consistent with providing quality health care". ${ }^{[13]}$ This raises the question: if Canadian hospitals were held accountable through accreditation standards, similar to their American counterparts, would they be further ahead in the area of tobacco reduction and smoke-free hospital property policies?

\subsection{A hospital's mission to foster health}

In the early to mid-2000's Canadian provinces and territories passed legislation to ban smoking in all enclosed public spaces and workplaces, including hospitals. ${ }^{[14]}$ The Joint Commission on Accreditation of Healthcare Organizations (JCAHO) in the United States implemented a similar standard almost a decade before this for all acute care hospitals to be smoke-free within their buildings by January, 1992. ${ }^{[6]}$ In Australia, a similar mandate was adopted in $1988 .{ }^{[15]} \mathrm{Al}-$ though a very positive step for hospitals, the unfortunate fallout to such policies (intended to reduce exposure to second hand smoke and promote cessation) ironically moved many individuals to smoke at every entrance. ${ }^{[16]}$ The optics of staff, patients and visitors smoking by the hospital entrances suggested to some that health facilities condone smoking. ${ }^{[1]}$ It has also been questioned whether smoking by the hospital entrances sends the wrong message about smoking or even creates the perception that health risks of smoking are exaggerated, especially when healthcare professionals are smoking on hospital property. ${ }^{[18]}$ Any visible smoking on hospital property also seems to starkly contradict the mission of a "healthcare" institution. ${ }^{[18]}$ Some suggest healthcare facilities have an even greater mandate in smoke-free policies as they are guided by their mission to foster health and protect patients and employees. ${ }^{[10]}$ With numerous patients hospitalized due to tobacco related disease along with many others being particularly vulnerable to the effects of ETS hospitals have a fundamental responsibility to do all they can to treat tobacco dependence and ensure a smoke-free environment. ${ }^{[10]}$

There are numerous health benefits to a $100 \%$ smoke-free hospital. ${ }^{[8,15]}$ Banning smoking on hospital properties creates an environment that protects individuals from exposure to ETS and supports those who are either trying to quit or who have quit smoking. This sends a clear message that smoking and exposure to ETS is harmful and not endorsed by the healthcare facility. Smoke-free hospital properties create opportunities to promote healthy choices, influence how tobacco use is managed and reduce the use of tobacco. ${ }^{[19]}$ For the Mental Health Centre Penetanguishene, the decision

Published by Sciedu Press to ban smoking on their hospitals property in 2003 was also quite pragmatic: a high number of patients needed to be escorted outside to smoke by staff, costing a significant amount in staff resources as well as staff exposure to ETS. ${ }^{[20]}$ They also did not want to be viewed as a facility that favored an activity known to be harmful to health. Furthermore, from a philosophical perspective, this facility questioned, "Can individual clinicians, all of whom belong to professional colleges that instruct their members to do their patients no harm, ethically facilitate smoking?"[20] Although some may argue that outdoor smoking bans are excessively controlling, others believe that beyond health justifications, the rationale reaches even further: fire risk, litter control, and continuity with a healthcare institution's mission to promote and protect health. ${ }^{[21]}$

\subsection{Hospitals are workplaces too}

Not only do we have to consider the benefits of a smoke-free property policy on the health of hospitalized patients, but also the individuals that ensure the operations of the hospital on a day-to-day basis. Unlike most patients with transient stays in hospital, hospital employees will work in these institutions for many years, if not their entire working life. Hospitals can not only be committed to fostering the health of their patients, but can also be a progressive employer caring for their staff's health and wellness. A study conducted by Unrod, Oliver, Heckman, Simmons, and Brandon ${ }^{[16]}$ exploring the attitudes and behaviors of employees both before and after hospital smoke-free property policy implementation, found significant differences in the expected negative impact and the actual impact of a smoke-free policy. Not surprisingly, the acceptance of a smoke-free policy was higher among non-smokers from the onset; yet acceptance among smokers increased after the policy was executed. ${ }^{[16]}$ Notably fewer employees that smoked actually reported the negative effects they anticipated in job satisfaction or mood once the policy was implemented. A substantial number of participants reported the policy had a positive impact on their ability to do their job, their interactions with others and their overall job satisfaction. ${ }^{[16]}$ This study also had a large number of employees that smoked who reported they were interested in quitting smoking before the ban (when it was just a smokefree building); this number actually doubled after the new policy was implemented, supporting that a $100 \%$ smoke-free property increases motivation to quit. ${ }^{[16]}$ They also found the number of cigarettes smoked by employees during the workday decreased, though one-third of those employees that continued to smoke did report a compensatory increase in smoking before and after work hours. ${ }^{[16]}$ These findings further support that workplace smoking bans reduce exposure to ETS and increase smoking cessation among employees. ${ }^{[16,21]}$ 


\section{Challenges to implementing AND ENFORCING HOSPITAL PROPERTY SMOKE-FREE POLICIES}

While a number of Canadian hospitals have taken a significant leadership role in the area of smoke-free hospital properties, unfortunately many are still hesitant and slower to act. In 2000, Bloch and Shopland ${ }^{[22]}$ from the National Cancer Institute debated the merits of outdoor smoking bans in an article published in Tobacco Control where they identified hospitals as stragglers in smoke-free property policy; disappointingly, 15 years later, the conversation in Canada has not drastically changed.

The reluctance to implement hospital property bans includes a multitude of reservations from many stakeholders, including administration, health professionals, staff, patients and families. Yet reassuringly, many concerns prior to smokefree policy implementation have not come to fruition after implementation. ${ }^{[16,17,22,25]}$ Compliance by staff, patients and visitors is one of the biggest challenges identified with a smoke-free property policy; ${ }^{[17,20]}$ however, concerns of such policies go beyond compliance issues to include leadership (or lack thereof), fears of negative public and staff perceptions, safety concerns and issues related to patient care, ${ }^{[23]}$ which will all be discussed here.

\subsection{Lack of compliance}

Compliance is a consistent challenge noted in the majority of the literature published on smoke-free hospital properties. ${ }^{[19,23,24]}$ There are many proposed explanations for this, including inadequate tobacco dependence treatment for patients and staff, inconsistent enforcement, lack of clear guidance for staff and DSA's that send mixed messages to stakeholders. ${ }^{[19,23]}$ In order to truly understand the issue of compliance, hospitals that have smoke-free property policies and those that have "comprehensive" smoke-free property policies first need to be differentiated. Many hospitals report they do have policies in place, but are lacking the critical infrastructure and systems needed for compliance. In much of the published literature to date, hospitals that have been studied have been generally referred to as "smoke-free", however, upon further examination many have a policy on paper with little support in place. Many lack consistencies with tobacco dependence supports or have incomplete bans, such as DSA's or exclusions to their policy. It is no surprise compliance is an issue in these situations.

Stockings et al. ${ }^{[25]}$ could only identify two psychiatric hospitals with comprehensive policies in their 2014 systematic review of the impact of smoke-free psychiatric hospitalizations on patient outcomes. Their findings ${ }^{[25]}$ suggested hos- pitals are only more recently starting to consider and implement comprehensive policies. This approach appears to be associated with more favorable outcomes including decreased smoking and policy adherence. ${ }^{[25]}$ This distinction was also identified by the Smoking and Health Action Foundation group,${ }^{[8]}$ whereby they argued that comprehensive smoke-free policies that include enforcement and tobacco dependence treatment will maximize policy success.

\subsection{Limited leadership}

Despite the overwhelming evidence of the negative health implications around tobacco use, the healthcare industry has been slow to tackle tobacco reduction in its own hospitals. ${ }^{[17]}$ Even though progress over the last decade has been made in offering patients brief smoking cessation advice, individual physicians, as well as other healthcare providers, are still not capitalizing on their positions of leadership to promote tobacco reduction initiatives. ${ }^{[17]}$ This is commonly demonstrated by the low rates of screening and brief advice offered to patients; just over half of patients receive advice by a physician to quit. ${ }^{[26]}$

The leadership of hospital administrators in tobacco reduction could also be examined to address the following excerpt: "A typical scene occurs daily as employees in scrubs stand on the front lawns of hospitals smoking, only to return inside shortly to take care of patients suffering from tobacco-related diseases". ${ }^{[17]}$ Physicians, healthcare professionals and hospital administrators not only have a responsibility to address tobacco use for both patients and staff, but also have a leadership opportunity to send a strong message about smoking and exposure to ETS. ${ }^{[17]}$

\subsection{Negative public and staff perception}

Many hospitals administrators are concerned smoke-free hospital property policies will create a negative public and staff perception. ${ }^{[17]}$ The image of patients suffering through nicotine withdrawal or pushing their intravenous poles off property to smoke has the potential to conjure up perceptions of an uncaring or judgmental hospital environment. ${ }^{[17]}$ There is also a perceived threat of smoke-free policies on staff morale and staff relations. ${ }^{[16,17]}$ A study exploring the impact of smoke-free hospital policies on employee and consumer behavior conducted by Wheeler et al. ${ }^{[17]}$ demonstrated after hospital smoke-free policies were implemented at two separate hospitals, there was undivided agreement by administrators that the ban was a positive change, despite their initial concerns. The concerns by administrators mentioned above were not realized; instead the administration reported an improved property appearance and image, a decrease in unwanted exposure to ETS and an increase in awareness of 
the negative health effects of ETS. The hospitals' leadership teams were applauded for their bravery to affect change; unfortunately, this was only after the implementation was completed. ${ }^{[17]}$

Along with staff morale and staff relations, the "rights" of employees that smoke are also regularly considered in the debate of smoke-free hospital properties. Hospital administrators may feel conflicted or concerned by implementing a policy that could appear ominous to their employees. ${ }^{[17]}$ As cited by Parle et al., ${ }^{[20]}$ the right to smoke has been challenged in the courts claiming violations of the Canadian Charter of Rights and Freedoms; however, these motions have been dismissed by the courts as there is no constitutional right to smoke; the charter does not protect individuals against perceived discrimination as a smoker. One such example was an arbitration case in British Columbia, cited by the Non-Smokers Rights Association, ${ }^{[27]}$ where employees felt the smoke-free policy unfairly discriminated against smokers. The Canadian labor relations board arbitrator supported there was no right to smoke, but did require the employer to ensure reasonable accommodations to avoid undue hardship. ${ }^{[27]}$ Providing accessible smoking cessation support for hospital employees will not only support their nicotine withdrawal and quit attempts but also support modeling the desired health behaviors to patients, as well as enhance credibility of the health information they convey to them. ${ }^{[13]}$

The Mental Health Center Penetanguishene was able to compellingly sum up their experience of transitioning to a $100 \%$ smoke-free property in one word: "liberation". [20] Patients were liberated from being controlled by tobacco; healthcare staff were liberated from enabling addiction and behaviors known to cause harm; housekeeping staff were liberated from cleaning up cigarette butts; doctors were liberated from treating preventable smoking related illness; and visitors, staff and fellow patients were liberated from walking through clouds of tobacco smoke at entrances of their hospital. ${ }^{[20]}$

\subsection{Safety concerns}

From a safety perspective, patients leaving the unit and property to smoke garners concerns by administrators and staff, as well as the patients themselves. ${ }^{[16,17,19,23,28]}$ While smokefree property policies do protect individuals from exposure to ETS, they do not provide safety for those that choose to leave the unit or property to smoke, often alone. ${ }^{[28]}$ Limited mobility and/or being connected to medical equipment, also contribute to these concerns. ${ }^{[19,23]}$ Some patients who feel the obstacles for leaving are too challenging then smoke in unauthorized areas within and outside of the hospital, which also raises additional safety concerns. ${ }^{[19,23]}$ In colder climates, such as in Canada, additional worries emerge around

Published by Sciedu Press patients not being properly dressed for the cold and the potential performance issues of medical equipment, such as IV lines and pumps. ${ }^{[19,23]}$

Leaving against medical advice waivers have been used by many hospitals to address the issue of safety; however, in a study conducted by Schultz et al., ${ }^{[23]}$ a qualitative investigation of smoke-free policies on hospital property, found these were used inconsistently. The utility of these forms to protect against liability, if a patient did get injured while off the property to smoke, has also been questioned. ${ }^{[28]}$ Harolds $^{[28]}$ advocated that preventing patients from leaving in the first place is the best way to ensure patient safety; which would entail screening of tobacco use on admission and managing nicotine withdrawal while in hospital. The University of Arkansas for Medical Sciences Hospital had similar safety concerns prior to implementing their smoke-free policy, yet after the implementation they found there was less traffic by patients going in and out to smoke. ${ }^{[17]}$ Many patients reported the safety risk and/or hassle to go off the property was not worth it and viewed a smoke-free policy as an opportunity to use their situation of being hospitalized to reduce or quit smoking. ${ }^{[19]}$

Healthcare staff and administrators also expressed fears that a smoke-free hospital property would lead to an increase in violence on nursing units. ${ }^{[17,20]}$ Although this may seem likely when patients are limited or unable to smoke, increases in violence have not been realized in hospitals that have implemented a comprehensive smoke-free policy that includes support for nicotine withdrawal. ${ }^{[20,29]}$ Even in psychiatric hospitals, where episodes of aggressive behavior may be more common, increases in violence has not been reported, "when consistent leadership, policy enforcement and systematic nicotine dependence treatment is given, bans have not lead to increased aggression or discharges against medical advice." ${ }^{[25]}$ The critical point being, nicotine withdrawal needs to be properly managed so that patients' nicotine cravings and withdrawal symptoms are minimized. An evaluation of a smoke-free 135-bed high-security forensic hospital in Australia conducted by Lawn et al. ${ }^{[29]}$ also found no increase in aggression or deterioration of mental health after a smokefree policy was implemented. They further suggested that smoke-free policies allow for more efficient use of staff resources: instead of monitoring tobacco use, staff had more time for therapeutic encounters that did not involve cigarettes as an incentive. ${ }^{[29]}$

\subsection{Patient-centred care concerns}

From a patient-centred perspective, smoking is often viewed as a patient's "only pleasure" during hospitalization. ${ }^{[20]}$ Limiting a patient's ability to smoke while hospitalized 
raises concerns that patients may not seek out treatment or that it could affect a patient's self-determination. ${ }^{[17,20]}$ As pointed out by members of the Mental Health Centre Penetanguishene's smoke-free task force, due to the addictive nature of nicotine, "choosing addiction" is not in keeping with self-determination. ${ }^{[20]}$ In reality, many smokers do not "choose" to smoke but are controlled by their cigarettes as a means to lessen the noxious symptoms of nicotine withdrawal. All healthcare professionals and healthcare facilities are in an instrumental position to support their patients to avoid engagement in harmful activities. Tobacco addiction is regularly underdiagnosed and still remains undertreated. ${ }^{[30]}$ Through greater understanding of the impact of smoking on health and by providing supports, such as nicotine withdrawal management, healthcare workers can enhance their patients' ability to make informed choices. ${ }^{[13]}$ Smoke-free policies have actually been shown to have a positive impact on patients' belief that they can quit, as well as their motivation to quit. ${ }^{[25]}$ This could suggest a supportive environment, such as one created by smoke-free polices, will actually enhance a patient's self-determination when it comes to making decisions about their health. When patient feedback was assessed during a study looking at the impact of a smoke-free campus at the University of Arkansas Medical Science hospital, they did not find any changes to patient satisfaction assessment scores or patient care scores when compared between pre-implementation and post-implementation of the policy. ${ }^{[17]}$ The authors of this study ${ }^{[17]}$ also found patient bed days and occupancy rates were slightly higher after implementation when comparing the 12-month means before and after policy implementation.

Shopik et al. ${ }^{[19]}$ corroborate that smoke-free hospital property polices have changed the context for those who do use tobacco. In a study they conducted to explore patient experiences of both smokers and non-smokers, it was unanimous among all participants that a smoke-free property policy sent a "strong de-normalization message". ${ }^{[19]}$ It was felt that it was a contradiction to the hospital's mandate to let individuals smoke on their property. While participants felt it important for protection from second hand smoke, in particular children and individuals suffering from illness, they also could empathize with those that did smoke and the impact a smoke-free policy would have on them. Although smokers agreed with the message a smoke-free policy conveyed about health, they also felt it was restrictive of their "right" to smoke, yet the inconvenience did make them think twice about smoking. They also acknowledged the hospital was a prime location to reduce their tobacco use. This supports earlier findings that smoke-free hospital properties create an environment that increases motivation to quit, makes it easier to quit and prevents relapse. ${ }^{[20]}$

There has been extensive debate about smoke-free policies in both the published literature and among hospital administrators and healthcare workers as it relates to patient-centred care in psychiatry. Some general hospitals have even chosen to exclude their psychiatry units from their smoke-free policies based on the notion that this population needs to smoke, somehow conceiving it is their only enjoyment. ${ }^{[20,23]}$ Others have even discouraged their psychiatry patients from quitting smoking out of fear of a relapse in their mental illness. ${ }^{[30]}$

Individuals with mental illness are two to four times more likely to smoke and tend to smoke more heavily when compared to the general population. ${ }^{[31]}$ This disproportionate rate of tobacco use makes individuals with mental illness even more susceptible to the devastation of tobacco use. Members of this vulnerable population are more likely to die from smoking related illnesses, such as cardiovascular disease, respiratory disease and cancer, than from their psychiatric conditions. ${ }^{[32]}$ While many believe this patient population should continue to smoke or not be offered tobacco dependence treatment, smokers with mental illness are indeed interested in quitting, similar to smokers without mental illness. $^{[30]}$ A multifaceted approach is needed, including treating both their physical and mental health, to ensure quality patient-centred care and improved patient outcomes. ${ }^{[32]}$ With a comprehensive approach to tobacco dependence, individuals with mental illness can be successfully treated. ${ }^{[30]}$ Psychiatry patients warrant the same holistic, quality of care that other patients are offered for smoking cessation. Even though many healthcare workers and caregivers feel they are protecting this marginalized population by advocating against smoke-free hospital policies, ironically, this patient group appears to be more stigmatized and vulnerable because of their mental illness, within the hospital setting.

In a systematic review of smoke-free psychiatric hospitalizations on patient outcomes, Stockings et al. ${ }^{[25]}$ found a significant reduction in the amount of cigarettes smoked during admission and a positive impact on motivation to quit, belief in ability to quit and ability to stay quit. This trend appeared to favor hospitals with complete smoke-free property bans (i.e. no DSA's) along with comprehensive nicotine dependence treatments, suggesting that adherence to smoking bans may be improved with this type of comprehensive approach. ${ }^{[25]}$ Another benefit for supporting tobacco dependence treatment in psychiatric facilities includes the ability to lower doses of certain psychiatric medications, which reduces side effects while offering the same clinical efficacy. ${ }^{[20]}$

Many discussions and studies exploring the merits of smoke- 
free hospital property policies focus primarily on the impact of such initiatives on patients that smoke, at times inadvertently overlooking the impact on patients that do not smoke (never smokers and former smokers). This is understandable as smoke-free polices will most likely have the greatest impact on hospitalized individuals that smoke and will raise the greatest concerns for their treatment and compliance. Although it is critical to realize the lived experiences of patients that do smoke, it is also important to appreciate the issue from the perspective of hospitalized patients that do not smoke but are unwillingly exposed to ETS. From this alternative perspective, a greater understanding of a smokefree hospital property can be achieved. Never smokers and former smokers have described their experiences to second hand smoke exposure at the entrances of the hospitals as "overwhelming". ${ }^{[19]}$ With tobacco rates declining over the last few decades, less hospitalized patients will currently smoke, even though many will be hospitalized due to tobacco related disease. When weighing the patient-centred care concerns of smoke-free hospital property policies, all patients' perspectives need to be considered.

\section{OPPORTUNitiES TO MAXIMIZE THE SUC- CESS OF SMOKE-FREE HOSPITAL PROP- ERTY POLICIES}

Preparation, planning and resources are needed to maximize opportunities for compliance and success with smoke-free hospital property policies. As discussed previously, a comprehensive smoke-free property policy, including tobacco dependence treatment for both patients and staff; elimination of policy exclusions and DSA's; as well as leadership and enforcement, will position hospitals to achieve the goals of reducing exposure to ETS, modeling healthy behaviors and promoting the harms of smoking. ${ }^{[8]}$ These three opportunities to maximize the success of smoke-free hospital property policies will be discussed in this section.

\subsection{Tobacco dependence treatment for patients and staff}

Tobacco dependence treatments have not only been shown to be clinically effective but also cost-effective relative to other medical and disease prevention interventions. ${ }^{[33]}$ Healthcare facilities are in a leadership position to take responsibility to treat the needs of their patients who are addicted to tobacco. ${ }^{[19]}$ As stated by Balmford et al., ${ }^{[13]}$ "Providing patients with relevant information, and trying to motivate them to change their behaviors in ways that will benefit their health is consistent with providing quality healthcare". Tobacco dependence treatments help individuals manage their withdrawal symptoms, quit smoking and get the supports they need to successfully abstain from smoking. ${ }^{[34]}$

Published by Sciedu Press
Although some may think smokers do not want to be questioned about their smoking, most hospitalized smokers, especially if they are in hospital due to a smoking related disease, will be receptive to an offer to assist with nicotine withdrawal management and smoking cessation. ${ }^{[13,34]}$ Nearly two-thirds of smokers report they are seriously considering quitting in the next 6 months. ${ }^{[35]}$ Most smokers will attempt to quit at least once, but the majority, contrary to their own wishes, will relapse within one year of quitting. ${ }^{[36]}$ This highlights the need for tobacco dependence to be viewed as a chronic condition often requiring repeated interventions to produce long-term abstinence. ${ }^{[33]}$ In a systematic review of interventions for smoking cessation in hospitalized patients, Rigotti et al. ${ }^{[34]}$ found hospitalized smokers, regardless of their reason for admission, were receptive to the offer of help for their smoking. Hospital-initiated smoking cessation programs provide a prime opportunity for healthcare providers to affect change in the lives of their patients. Hospital-based tobacco dependence treatments are effective for quitting smoking, and offering nicotine replacement therapy further increases success rates. ${ }^{[34]}$

The Canadian smoking cessation clinical practice guidelines developed by the Canadian Action Network for the Advancement, Dissemination and Adoption of Practice-informed Tobacco Treatment (CAN-ADAPTT) ${ }^{[37]}$ support the critical role of tobacco dependence treatment, including nicotine withdrawal management and smoking cessation supports, for patients during hospital admission. In fact, they recommend patients being admitted for elective treatments should also be directed to smoking cessation resources prior to admission. All hospitals could have a system in place to screen for tobacco use, manage nicotine withdrawal during admission to hospital (including use of pharmacotherapy) and promote benefits of smoking cessation along with follow up supports after discharge. A critical component for sustainable tobacco treatment by hospital management and staff is to ensure training and resources including: standing orders, medical directives and allocated staff. ${ }^{[37]}$ Approaches for tobacco treatment may differ between a smoker that wants to quit (i.e. smoking cessation), versus one that does not (i.e. nicotine withdrawal management); however, both can be very effective in supporting individuals while hospitalized within a smoke-free hospital campus. If patients are not experiencing nicotine withdrawal, their desire to leave the property to smoke or violate a smoke-free policy is mitigated. This ultimately will improve compliance and help to achieve the goal of decreasing the exposure of the greater hospital population to ETS. ${ }^{[19]}$

Tobacco treatment is still not a standard of care in many healthcare institutions. ${ }^{[8,23]}$ Even though several hospitals re- 
port implementing smoking cessation screening and supports for their inpatients, many hospitalized patients that smoke do not receive treatment. Equally as concerning is the paucity of health professionals that offer these interventions. ${ }^{[8,23,26]}$ Many healthcare professionals report feeling inadequately trained to provide tobacco dependence assistance; however, regardless of in-depth training, even brief advice (if provided) will help move individuals towards an attempt to quit smoking. [13,38,39]

A joint position statement on the role of health professionals in tobacco cessation ${ }^{[40]}$ was released in 2011 and developed jointly by the Canadian Association of Occupational Therapists, Canadian Counselling and Psychotherapy Association, Canadian Dental Hygienists Association, Canadian Medical Association, Canadian Nurses Association, and Canadian Physiotherapy Association. One of the key recommendations highlighted in the position statement is for every Canadian health professional to play a role in tobacco reduction, including assessing and documenting tobacco use, offering assistance to quit, providing referrals to smoking cessation resources and using a collaborative, interdisciplinary approach. Based on the 2014 Tobacco Use in Canada: Patterns and Trends report, ${ }^{[26]}$ the percentage of smokers that received advice to quit from health care professionals, such as, physicians and pharmacists, ranged from only $13 \%$ to $56 \%$. In a time-constrained health care system, brief intervention for smoking cessation has been shown effective in helping individuals quit smoking. ${ }^{[41]}$ As previously mentioned, staff training on tobacco treatment and standardized protocols are important elements to improve the management of patient's nicotine withdrawal. Clearly these initiatives also support the successful implementation of a smoke-free policy.

While some would advocate a 100\% smoke-free hospital property ban forces patients to quit against their will or impinges on their "rights", ${ }^{[42]}$ others propose it's wrong to permit patients to harm their health or interfere with their treatment while under medical supervision. ${ }^{[22]}$ Shopik et al. ${ }^{[19]}$ explore the patients' experiences and perceptions of smoke-free hospital ground policies, suggesting that unless tobacco addiction is addressed optimally a smoke-free property will not be successful. They propose that tobacco dependence may need to be reframed from cessation to abstinence in some cases, in order to manage their nicotine withdrawal while in hospital. Even temporary abstinence will improve current health conditions and reduce safety risks for individuals that must leave the property to smoke. ${ }^{[19]}$ The authors advocate more research is needed to explore this topic in hospital environments and call for continued research in this area to inform tobacco dependency best practices and to determine how this impacts smoke-free hospital property compliance. ${ }^{[19]}$

From an administrative perspective, hospitals also need to be accountable for both productivity and the bottom line. Employee smoking is associated with significant losses in productivity, including unsanctioned smoke breaks, additional sick days, as well as a higher likelihood of short and long-term disability claims. ${ }^{[43]}$ It is estimated that employees who smoke take two additional smoke breaks per day representing an average of 40 minutes of unsanctioned breaks. The Conference Board of Canada ${ }^{[43]}$ suggest these estimates are conservative when compared to other survey data that indicates employees take an average of four unsanctioned smoke breaks per day, at 15 minutes each. As well, with a higher risk for chronic conditions, infections and illnesses, employees are also more likely to take additional sick days. ${ }^{[43]}$ In 2012, the Conference Board of Canada ${ }^{[43]}$ estimated the average costs to an employer of unsanctioned smoke breaks and absenteeism was $\$ 4,256$ annually for each employee that smoked daily, based on an hourly wage of $\$ 22.42$. With a national smoking prevalence of almost $15 \%$, the losses to an organization can add up quickly. These estimates do not even take into account the costs of short and long-term disability claims or premature mortality. Strategic investments and support for employee tobacco reduction and dependence treatments provide the opportunity to benefit both the employee and the hospital. ${ }^{[43]}$ Key to improve smoke-free property policy compliance is the availability of supports for nicotine withdrawal/smoking cessation for not only patients, but also for hospital staff. ${ }^{[29]}$ Workplaces are optimal and effective settings to help individuals quit smoking as a large number of people can be reached using proven tobacco reduction methods. ${ }^{[44]}$

\subsection{Elimination of policy exclusions and DSA's}

Based on many of the above mentioned concerns, some hospitals have implemented smoke-free property polices with exclusions for different patient groups within the hospital, such as psychiatry, palliative care and the emergency department. ${ }^{[23]}$ Some support this approach and feel hospitals should not only have exceptions for certain populations but have DSA's for anyone that wants to smoke while at the hospital. ${ }^{[18]}$ Although many have suggested this would be a more empathetic approach to dealing with smoking on hospital property, as well as addressing other concerns such as safety, a designated smoking area is not consistent with the mission of hospital institutions and still sends the wrong message concerning the use of tobacco and health. ${ }^{[23]}$ A complete smoke-free hospital policy including buildings and property without allowing for exclusions is considered the "ultimate standard" that all hospitals should adopt. ${ }^{[45]}$ Founded on their 
own lived experiences, some report that hospitals that take a partial approach (such as DSA's or exclusions) will spend a substantial amount of unnecessary resources and time on this issue. ${ }^{[20]}$ Accounts from both their patients and staff supported a $100 \%$ smoke-free environment made it easier to quit smoking or not smoke while on the property. With mixed messages given through partial bans or DSA's, "It's ok to smoke there, but not here", it's not surprising to see individuals that smoke violating the policy by smoking in no-smoking areas or creeping closer to the front doorways of the hospital. Enforcing a partial ban is more difficult than enforcing a full hospital property ban when there are proper supports and systems in place. ${ }^{[25]}$

A Canadian study by Schultz et al. ${ }^{[23]}$ explored two hospitals that had implemented smoke-free property policies; however, exemptions were granted for palliative care units and psychiatry units and one hospital also allowed supervised smoking outside of the emergency department. Upon examination, the authors of this study reported many compliance violations to the smoke-free policy. Other concerns included increased litter and the perception of minimal security enforcement. This suggests a partial ban with DSA's may send a mixed message to smokers as well as to others expected to enforce the policy.

\subsection{Leadership and enforcement}

There is a need to build awareness across the organization before a smoke-free policy goes into effect. ${ }^{[17]}$ Smoke-free policies also need to be "unambiguous and consistently implemented"; the hospital's leadership team needs to endorse the policy and portray unwavering policy support. ${ }^{[29]}$ A hospitalwide approach needs to ensure consistent, free-flowing communication with all stakeholders, clear expectations, training and education for staff (including security staff) and strategically placed signage. ${ }^{[8,10,29,46]}$ Framing smoking as an addiction can also help elevate smoking into the context of an addiction rather than a simple habit, which will enable healthcare professionals to feel more capable to offer supports, such as nicotine withdrawal management. ${ }^{[23]}$ Messaging should be positive, such as "smoke-free" versus "smoking ban" and patients and community should be informed prior to admission as well as upon admission/visitation to the hospital grounds. ${ }^{[10]}$ After a smoke-free policy is implemented, there is a need to ensure compliance issues are consistently monitored and addressed in order to further enforce policy adherence and maximize success. ${ }^{[10]}$

\section{Conclusion}

The progression of smoke-free hospital policies can be put into context by examining the long history of how hospitals have slowly gone from selling tobacco within its walls, to limiting smoking in hospitals, to smoke-free hospital buildings, to designated outdoor smoking areas, and eventually to $100 \%$ smoke-free hospital properties. Today, some hospitals in Canada have transitioned to smoke-free properties and are leading by example; however, many still allow smoking in designated areas or do not have any policies in place other than current provincial legislation for public buildings. Fear, speculation and reservation appear to be what is stalling the progress in many healthcare facilities across Canada, yet the majority of these concerns are unfounded. As discussed, there will be challenges to making a hospital property smoke-free, nevertheless, the evidence supporting the implementation of comprehensive smoke-free hospital property policies far outweighs the concerns.

With overwhelming evidence of disease and death caused by tobacco use in our society, many Canadian hospitals still need to do more. We cannot rest on the successes from the past or base our current actions on unsubstantiated fears, in hopes for a better tomorrow. Hospitals are ideal institutions to continue the downward trend in tobacco use prevalence. Through smoke-free property policies, Canadian hospitals can make a significant impact and lead by example in their communities by creating opportunities to promote healthy choices, protecting individuals from exposure to ETS, supporting those who are trying to quit or who have quit smoking and by sending a clear message that smoking and exposure to tobacco smoke is harmful. ${ }^{[8,15,17]}$ As we have witnessed though the successes of leading hospitals, transitioning to a smoke-free hospital property is achievable. With the combined strength of human will and best evidence, there is a way to achieve healthier healthcare settings!

\section{ACKNOWLEDGEMENTS}

Special thanks to my PhD supervisor, Dr. Shelley Doucet, UNBSJ, and committee member Dr. Robert Stevenson, New Brunswick Heart Center, for their support and feedback.

\section{CONFlicts of InTEREST Disclosure}

There are no competing interests in this paper. 


\section{REFERENCES}

[1] Krueger H, Krueger JK, Koot J. Variation across Canada in the economic burden attributable to excess weight, tobacco smoking and physical inactivity. Can J Public Health. 2015; 106(4): E171-77. http://dx.doi.org/10.17269/cjph.106.4994

[2] Strong foundation, renewed focus: an overview of Canada's federal tobacco control strategy 2012-17 [internet]. Ottawa (ON): Health Canada; 2012 [updated 2014 Jan 23; cited 2016 Mar 5]. Available from: http://www.hc-sc.gc.ca/hc-ps/pubs/tobac-tabac /fs-sf/index-eng.php

[3] The Health Consequences of Smoking: 50 Years of Progress. A Report of the Surgeon General [internet]. Atlanta, GA: U.S. Department of Health and Human Services, Centers for Disease Control and Prevention, National Center for Chronic Disease Prevention and Health Promotion, Office on Smoking and Health, 2014; 2014 Jan [cited 2016 Feb 4]. Available from: http://www.surgeongeneral.gov/library/reports /50-years-of-progress/full-report.pdf

[4] Summary of results for 2013 Canadian tobacco, alcohol and drugs survey [internet]. Ottawa (ON): Government of Canada; 2014 [updated 2015 Feb; cited 2016 Feb]. Available from: http://healthycanadians.gc.ca/science-research-sci ences-recherches/data-donnees/ctads-ectad/summary - sommaire-2013-eng.php

[5] A National Strategy [internet]. Ottawa (ON): Health Canada 1999 [archived 2013 Jun 24; cited 2016 Feb 12]. Available from: http://www.hc-sc.gc.ca/hc-ps/pubs/tobac-tabac /ns-sn/index-eng · php\#exec

[6] Williams SC, Hafner JM, Morton DJ, et al. The adoption of smokefree hospital campuses in the united states. Tob Control. 2009; 18(6): 451-458. http://dx.doi.org/10.1136/tc.2009.030494

[7] Patterson PB, Hawe P, Clarke P, et al. The worldview of hospital security staff: Implications for health promotion policy implementation. J Contemp Ethnogr. 2009; 38(3): 336-357.

[8] The evolution of smoke-free hospital properties [internet]. Toronto (ON): Smoking and Health Action Foundation; 2013 [cited 2016 Feb]. Available from: https://www.nsra-adnf.ca/cms/file/ files/Evolution_of_S-F_hospitals_2013-FINAL(1).pdf

[9] Smoke-free Ontario act [internet]. Toronto (ON): Government of Ontario; 2016 [cited 2016 Feb 1]. Available from: https ://www ontario.ca/laws/regulation/060048\#BK15

[10] Fox SD, Shovein J. Achieving smoke-free hospitals: tips for administrators. Hosp Top. 1993; 71(3): 29-32. PMid: 10129078 http://dx.doi.org/10.1080/00185868.1993.9950556

[11] Standards FAQs: smoke-free Campus [internet]. Oak Brook (IL): The Joint Commission; 2008 [cited 2016 Feb 3]. Available from: http: //www.jointcommission.org/standards_information/jc faqdetails . aspx?StandardsFaqId=628\&ProgramId=47

[12] Corporate overview [internet]. Ottawa (ON): Accreditation Canada; 2013 [cited 2016 Feb 4]. Available from: https : //accreditatio n.ca/corporate-overview

[13] Balmford J, Leifert JA, Jaehne A. "Tobacco dependence treatment makes no sense because"... : Rebuttal of commonly-heard arguments against providing tobacco dependence treatment in the hospital setting. BMC Public Health. 2014; 14: 1182. http://dx.doi.org/1 $0.1186 / 1471-2458-14-1182$

[14] Smoking ban legislation in Canadian provinces and municipal bylaws in selected cities [internet]. Ottawa (ON): Statistics Canada; 2008 [cited 2016 Feb 6]. Available from: http://www.statcan.gc.ca/pub/82-003-x/2006008/art icle/smoking-tabac/t/4060721-eng.htm
[15] Nagle AL, Schofield HJ, Redman S. Smoking on hospital grounds and the impact of outdoor smoke-free zones. Tob Control. 1996; 5: 199-204. http://dx.doi.org/10.1136/tc.5.3.199

[16] Unrod M, Oliver JA, Heckman BW, et al. Outdoor smoking ban at a cancer center: Attitudes and smoking behavior among employees and patients. J Public Health Manag Pract. 2012; 18(5): E24-31. http://dx.doi.org/10.1097/PHH.0b013e31822d4bb5

[17] Wheeler JG, Pulley L, Felix HC, et al. Impact of a smoke-free hospital campus policy on employee and consumer behavior. Public Health Rep. 2007; 122(6): 744-753. PMid: 18051667.

[18] Jones TE, Williams J. Smoking prevalence and perspectives on smoking on campus by employees in Australian teaching hospitals. Intern Med J. 2012; 42(3): 311-316. http://dx.doi.org/10.1111/j $.1445-5994.2010 .02221 . \mathrm{x}$

[19] Shopik NA, Schultz AS, Nykiforuk CI, et al. Impact of smokefree hospital grounds policies: Patient experiences and perceptions. Health Pol. 2012; 108(1): 93-99. http://dx.doi.org/10.1016 /j.healthpol.2012.08.006

[20] Parle D, Fleming R, Gagné J, et al. Going 100\% smoke-free in a secure setting: One hospital's successful experience. Healthc Q. 2004; 7(2): 42-48. http://dx.doi.org/10.12927/hcq. 2004.16620

[21] Callinan JE, Clarke A, Doherty K, et al. Legislative smoking bans for reducing second hand smoke exposure, smoking prevalence and tobacco consumption. Cochrane Database Syst Rev. 2010; 4. http://dx.doi.org/10.1002/14651858.CD005992

[22] Bloch M, Shopland DR. Outdoor smoking bans: More than meets the eye. Tob Control. 2000; 9: 99. http://dx.doi.org/10.1136 /tc. 9.1.99

[23] Schultz AS, Finegan B, Nykiforuk CI, et al. A qualitative investigation of smoke-free policies on hospital property. CMAJ. 2011; 183(18): E1334-44. http://dx.doi.org/10.1503/cmaj.1102 35

[24] Ratschen E, Britton J, McNeill A. Smoke-free hospitals-the English experience: Results from a survey, interviews and site visits. BMC Health Serv Res. 2008; 8: 41. http://dx.doi.org/10.1186/1 472-6963-8-41

[25] Stockings EA, Bowman JA, Prochaska JJ, et al. The impact of a smoke-free psychiatric hospitalization on patient smoking outcomes: A systematic review. Aust N Z J Psychiatry. 2014; 48(7): 617-633. http://dx.doi.org/10.1177/0004867414533835

[26] Reid JL, Hammond D, Rynard VL, et al. Tobacco use in Canada: Patterns and trends, 2014 edition. Waterloo, (ON): Propel Centre for Population Health Impact, University of Waterloo; 2014. Available from: http://www.mantrainc.ca/assets/tobaccou seincanada_2014.pdf

[27] Canadian case law on drifting second-hand smoke in multi-unit dwellings [internet]. Toronto (ON): Non-Smokers Rights Association; 2007 [cited 2016 Feb 6]. Available from: http://www.nsra-adnf .ca/cms/file/files/pdf/Cana dian_drift_smoke_case_law_March_2007.pdf

[28] Harolds LB. Hospital safety for women with nicotine addiction. Nurs Womens Health. 2015; 19(4): 357-363. http://dx.doi.org/10. 1111/1751-486X.12222

[29] Lawn S, Hehir A, Indig D, et al. Evaluation of a totally smoke-free forensic psychiatry in-patient facility: Practice and policy implications. Aust New Zealand Health Policy. 2014; 38(4): 476-482. http://dx.doi.org/10.1071/AH13200

[30] Els C, Kunyk D. Management of tobacco addiction in patients with mental illness. Smoking Cessation Rounds [internet]. 2008; 2(2). Available from: http://v1.poumon.ca/crc/pdf/CEls2of3.pd f 
[31] Ziedonis D, Hitsman B, Beckham JC, et al. Tobacco use and cessation in psychiatric disorders: National Institute of mental health report. Nicotine Tob Res. 2008; 10(12): 1691-715. http://dx.doi . org/10.1080/14622200802443569

[32] Lawrence D, Hancock KJ, Kisely S. The gap in life expectancy from preventable physical illness in psychiatric patients in Western Australia: Retrospective analysis of population based registers. BMJ. 2013; 346: 1-14. http://dx.doi.org/10.1136/bmj .f2539

[33] Fiore FC, Jaén CR, Baker TB, et al. Treating tobacco use and dependence: 2008 update. Clinical practice guideline [internet]. Rockville, MD: U.S. Department of Health and Human Services Public Health Service; 2008 [cited 2016 Feb 4]. Available from: http://www.ahrq.gov/professionals/clinicians-provi ders/guidelines-recommendations/tobacco/index.html

[34] Rigotti NA, Clair C, Munafò MR, et al. Interventions for smoking cessation in hospitalized patients. Cochrane Database of Syst Rev. 2012; 5: CD 001837. http://dx . doi .org10.1002/14651858.C D001837 . pub3

[35] Reid JL, Hammond D, Rynard VL, et al. Tobacco Use in Canada: Patterns and Trends, 2015 Edition.Waterloo, ON: Propel Centre for Population Health Impact, University of Waterloo; 2015 [cited 2016 Feb 2]. Available from: http://www.tobaccoreport.ca/2015/ TobaccoUseinCanada_2015.pdf

[36] Hughes JR, Keely J Naud S. Shape of the relapse curve and long term abstinence among untreated smokers. Addiction. 2004; 99(1): 29-38. http://dx.doi.org/10.1111/j.1360-0443.2004.00540.x

[37] Canadian smoking cessation clinical practice guideline. Toronto, (ON): Canadian Action Network for the Advancement, Dissemination and Adoption of Practice-informed Tobacco Treatment, Centre for Addiction and Mental Health; 2011 [cited 2016 Feb 10]. Available from: https://www.nicotinedependenceclinic.c om/English/CANADAPTT/Documents/CAN-ADAPTT $\% 20$ Canadi an $\% 20$ Smoking $\% 20$ Cessation $\% 20$ Guideline_website.pdf
[38] Rice VH, Hartmann-Boyce J, Stead LF. Nursing interventions for smoking cessation. Cochrane Database Syst Rev. 2008(1): CD001188. http://dx.doi.org/10.1002/14651858.CD0011 88. pub3

[39] Stead LF, Buitrago D, Preciado N, et al. Physician advice for smoking cessation. Cochrane Database Syst Rev. 2008(2): CD000165. http://dx.doi.org/10.1002/14651858.CD000165.pub3

[40] Position statement: the role of health professionals in tobacco cessation [internet]. Ottawa $(\mathrm{ON})$ : Canadian Association of Occupational Therapists; 2011[cited 2016 Feb 19]. Available from: http: //www . caot. ca/default . asp?pageid=245

[41] Stead LF, Bergson G, Lancaster T. Physician advice for smoking cessation. Cochrane Database Syst Rev. 2008(2): CD000165. http://dx.doi.org/10.1002/14651858.CD000165.pub3

[42] Chapman S. Banning smoking outdoors is seldom ethically justifiable. Tob Control. 2000; 9: 95-97. http://dx.doi.org/10.1136 /tc.9.1.95

[43] Bounajm F, Stonebridge C, Theriault L. Smoking cessation and the workplace: Briefing 3-benefits of workplace programs. Ottawa (ON): The Conference Board of Canada; 2013 [cited 2016 Feb 16]. Available from: http://www. conferenceboard.ca/e-lib rary/abstract . aspx?did=5838

[44] Cahill K, Lancaster T. Workplace interventions for smoking cessation. Cochrane Database Syst Rev. 2008(4): CD003440. http: //dx.doi.org/10.1002/14651858.CD003440.pub3

[45] McNeil A, Owen L. Guidance for smoke-free hospital trusts. London (Eng): Health Development Agency; 2005 [cited 2016 Feb 20]. ISBN 1-84279-315-2. Available from: https://www . bipsolutions.c om/docstore/pdf/9406.pdf

[46] Gajendra S, Ossip DJ, Panzer RJ, et al. Implementing a smoke-free campus: A medical center initiative. J Community Health. 2011; 36(4): 684-692. http://dx.doi.org/10.1007/s10900-011-9 361-y 